\title{
Métodos para determinação da dinâmica de perfilhamento de Panicum maximum cv. Tanzânia
}

\author{
Methods to determine the tillering dynamics in Panicum \\ maximum cv. Tanzania
}

\begin{abstract}
Camila Fernandes Domingues Duarte ${ }^{1^{*}}$, Luísa Melville Paiva ${ }^{2}$, Henrique Jorge Fernandes ${ }^{2}$, Thiago Trento Biserra ${ }^{1}$, Alex Coene Fleitas ${ }^{3}$, Ademir Oliveira da Silva ${ }^{3}$

${ }_{1}^{1}$ Programa de Pós-Graduação em Zootecnia, Universidade Estadual de Mato Grosso do Sul (UEMS), Aquidauana, MS, Brasil ${ }^{2}$ Docentes dos cursos de graduação e pós-graduação em Zootecnia, Universidade Estadual de Mato Grosso do Sul (UEMS), Aquidauana, MS, Brasil

${ }^{3}$ Graduação em Zootecnia, Universidade Estadual de Mato Grosso do Sul (UEMS), Aquidauana, MS, Brasil
\end{abstract}

\section{Resumo}

Objetivou-se avaliar formatos de moldura metálica na coleta de dados para determinação da dinâmica de perfilhamento de capim-tanzânia. 0 experimento foi realizado no Setor de Agrostologia da Fazenda UEMS, em Aquidauana, MS, em delineamento, em blocos casualizados em canteiros já implantados de Panicum maximum cv. Tanzânia, durante o outono de 2014, comparando molduras de $0,0625 \mathrm{~m}^{2}$, identificandose perfilhos vivos, mortos e novos. Após esta medida foram estimadas as taxas de aparecimento, mortalidade e sobrevivência de perfilhos. Analisaram-se os dados, verificando-se o efeito do método de coleta sobre as estimativas, utilizando-se o PROC GLM do SAS. Além disto, avaliou-se a regressão dos dados obtidos com a moldura retangular em função dos dados obtidos com o quadrado, e avaliou-se o coeficiente de determinação, o teste $\mathrm{F}$ simultâneo para identidade de parâmetros $(\mathrm{a}=0$ e $b=1$ ) e a raiz do quadrado médio do erro da predição. Calculou-se ainda a correlação de ranking de Spearman para avaliar se o ranking das produções seria semelhante entre os métodos. A análise de variância mostrou que o formato da moldura metálica não afetou $(\mathrm{p}>0,05)$ as estimativas estudadas. Conclui-se que os diferentes formatos de molduras utilizadas não interferem na coleta de dados para determinação da dinâmica de perfilhamento do capim-tanzânia.

Palavras-chave: Característica estrutural. Metodologia de contagem de perfilhos. Padrão demográfico de perfilhos. Perfilhos.

\begin{abstract}
The objective of this study was to evaluate metallic frame formats in the data collection to determine the dynamics of tillering of tanzania grass. The experiment was carried out in the Agricultural Sector of the UEMS Farm, in Aquidauana
\end{abstract}


- MS. The experiment was developed in a randomized complete block design with already implanted beds of Panicum maximum cv. Tanzania, during the autumn of 2014, comparing frames of 0,0625 m2, identifying live, dead and new tillers. After this measure the rates of onset, mortality and tiller survival were estimated. The data were analyzed, and the effect of the collection method on the estimates was verified using SAS PROC GLM. In addition, we evaluated the regression of the data obtained with the rectangular frame as a function of the data obtained with the square, and the coefficient of determination, the simultaneous $F$-test for parameter identity $(a=0$ and $b=$ 1) and the root mean square of the prediction error. The Spearman rank correlation was also calculated to evaluate if the ranking of the productions would be similar between the methods. The analysis of variance showed that the shape of the metallic frame did not affect $(p>0.05)$ the estimates studied. It is concluded that the different formats of frames used do not interfere in the data collection to determine the dynamics of tillering of tanzania grass.

Keywords: Structural characteristic. Methodology for tiller counting. Tiller's demographic pattern. Tillers.

\section{Introdução}

As pastagens, segundo Hodgson (1990), são formadas por populações de plantas que, em gramíneas forrageiras, têm os perfilhos como unidade básica de desenvolvimento. Estas unidades apresentam tempo de vida limitado, devido à decapitação dos pontos de crescimento, sendo o pastejo ou o corte as principais causas de mortalidade.

O entendimento de como o processo de formação da produção primária ocorre em comunidades de plantas forrageiras é fundamental para que decisões sobre como explorá-las sejam tomadas com embasamento técnico-científico e para que possam ser usufruídas como recurso econômico (Pedreira et al., 2006). A definição de manejo de acordo com a ecofisiologia da planta permite um melhor entendimento da produção vegetal. Difante et al. (2008) afirmam que a compreensão do processo de acúmulo de forragem de um pasto, aliado às diferentes respostas ao processo de pastejo, determinará o conhecimento das respostas das gramíneas tropicais ao manejo que são impostas.

Outro importante fator para a produção em pasto é a perenidade das gramíneas forrageiras que, segundo Barbosa et al. (1996), é garantida pela capacidade em rebrotar após cortes ou pastejos sucessivos. Essa capacidade de regeneração do tecido foliar é realizada pelo perfilhamento, através da emissão de perfilhos dos meristemas apicais e das gemas axilares (Freitas, 2000).

Hay et al. (2000) sugeriram um método para estimar a dinâmica populacional de perfilhos em plantas forrageiras. 0 método consiste em fazer a contagem dos perfilhos vivos, mortos, aéreos e reprodutivos a cada 28 dias, em uma área representativa da unidade experimental. Os autores utilizaram armações metálicas quadradas de 0,0625 $\mathrm{m}^{2}$ em gramíneas forrageiras temperadas.

No entanto, as plantas forrageiras tropicais diferem das temperadas e de outras espécies tropicais quanto as suas características morfológicas, morfogênicas, estruturais e fisiológicas. Assim, fica evidente a necessidade de armação para contagem de perfilhos com formato e área que se adequem às peculiaridades das forrageiras tropicais.

Atualmente não existem trabalhos que comparem a eficiência da utilização de armações metálicas retangulares ou quadradas, nem se algum formato expressa melhor o perfilhamento de plantas forrageiras tropicais. Neste sentido, o objetivo deste trabalho foi comparar os formatos quadrangular e retangular da moldura (armação) metálica na dinâmica de perfilhamento de capim-tanzânia.

\section{Material e métodos}

As avaliações foram realizadas no Setor de Agrostologia da Fazenda UEMS, em Aquidauana, MS, localizada a $20^{\circ} 28^{\prime}$ de latitude sul e a uma longitude de $55^{\circ} 48^{\prime}$ a oeste de Greenwich, apresentando altitude média de $149 \mathrm{~m}$.

As coletas das informações, feitas em canteiros já implantados de Panicum maximum cv. Tanzânia, foram realizadas durante quatro meses, a cada 28 dias. Em cada ponto de coleta era alocada a moldura quadrada e contados e identificados os perfilhos. 0 mesmo procedimento era realizado com o retângulo. 
Assim considerou-se a média das coletas para a avaliação de dados, e utilizaram-se os dados de cada material com a média dos quatro dias avaliados. As coletas foram desenvolvidas conforme a Figura 1.
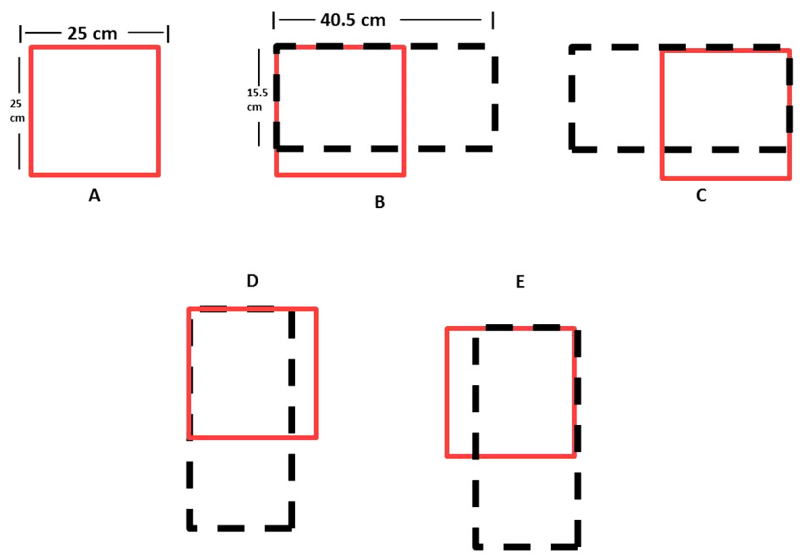

Nota: $\mathrm{A}$ = primeira contagem dos perfilhos utilizando apenas o quadrado. $B=$ segunda contagem dos perfilhos utilizando o retângulo posicionado no sentindo oeste-leste. $C$ = terceira contagem dos perfilhos utilizando 0 retângulo posicionado no sentindo leste-oeste. $D=$ quarta contagem dos perfilhos utilizando o retângulo posicionado no sentindo norte-sul. $\mathrm{E}=$ quinta contagem dos perfilhos utilizando o retângulo posicionado no sentindo sul-norte.

Figura 1 - Contagem dos perfilhos nas diferentes molduras (quadrado e retângulo).

$\mathrm{Na}$ área onde foram implantadas as parcelas, realizou-se coleta de solo para análise química e física. A área foi gradeada, cada parcela corrigida para $\mathrm{V} \%=50 \%$ e a adubação fosfatada realizada para que todos recebessem $14 \mathrm{mg} \mathrm{dm}^{-3} \mathrm{de} \mathrm{P}$.

Uma semana após a adubação foi realizada a semeadura da forrageira em linhas, sendo seis linhas por parcela. Cinquenta dias após a semeadura foi realizada adubação nitrogenada, com o equivalente a $100 \mathrm{~kg} \mathrm{ha}^{-1}$ de N, em todos os canteiros.

No início da estação chuvosa (dezembro) do ano de 2013, realizou-se adubação nitrogenada de manutenção nas parcelas, com $100 \mathrm{~kg} \mathrm{ha}^{-1}$ de N. Quando as plantas atingiram cerca de $50 \mathrm{~cm}$ de altura média, realizou-se o corte de uniformização a $20 \mathrm{~cm}$ de altura do solo. Os dados foram coletados durante o outono de 2014. As temperaturas máxima e mínima, precipitação média e horas de luz diária estão apresentadas na Tabela 1.

Comparou-se as molduras de formato quadrado e retângulo de $0,0625 \mathrm{~m}^{2}$ na dinâmica de perfilhamento, confeccionadas com vergalhões. A contagem dos perfilhos foi realizada a cada 28 dias, sendo estes classificados em basilares (DPPb) ou aéreos (DPPa), de acordo com a gema que deu origem ao mesmo, reprodutivos (DPPr), quando houve a presença de inflorescência, e perfilhos mortos.

Tabela 1 - Média da duração de luz diária, temperaturas mínima e máxima, e precipitação durante o outono de 2014

\begin{tabular}{ccccc}
\hline $\begin{array}{c}\text { Estação } \\
\text { do ano }\end{array}$ & $\begin{array}{c}\text { Média luz } \\
\text { diária }(\mathrm{h})\end{array}$ & $\begin{array}{c}\text { Tempertura } \\
\text { mínima }\left({ }^{\circ} \mathrm{C}\right)\end{array}$ & $\begin{array}{c}\text { Tempertura } \\
\text { máxima }\left({ }^{\circ} \mathrm{C}\right)\end{array}$ & $\begin{array}{c}\text { Precipitação } \\
\text { média }(\mathrm{mm})\end{array}$ \\
\hline Outono & 11 & 15 & 28 & 300 \\
\hline
\end{tabular}

Fonte: CEPTEC (2014).

Para determinação da dinâmica de perfilhamento foram estimadas as taxas de aparecimento, mortalidade e sobrevivência de perfilhos basilares e aéreos (TxAp, TxMort, TxSobr), e utilizadas as fórmulas:

- $\operatorname{TxAp}$ (taxa de aparecimento de perfilhos) = $\left\{\left[\left(\mathrm{n}^{\circ}\right.\right.\right.$ de perfilhos novos marcados $/ \mathrm{n}^{\circ}$ total de perfilhos vivos na marcação anterior) x 100$] / \mathrm{n}^{\circ} \mathrm{de}$ dias do ciclo\}.

- TxMort (taxa de mortalidade de perfilhos) = $\left\{\left[\left(\mathrm{n}^{\circ}\right.\right.\right.$ de perfilhos mortos $/ \mathrm{n}^{\circ}$ total de perfilhos vivos na marcação anterior) x 100] $/ \mathrm{n}^{\circ}$ de dias do ciclo\}.

- $\operatorname{TxSobr}$ (taxa de sobrevivência de perfilhos) = 1- TxMort.

0 delineamento experimental utilizado foi o de blocos casualizados. Analisaram-se os dados, verificando-se o efeito do método de coleta sobre as estimativas, utilizando-se o PROC GLM do SAS (2009). Além disto, avaliou-se a regressão dos dados obtidos com a moldura retangular em função dos dados obtidos com o quadrado equilátero (Tedeschi, 2006), e avaliou-se o coeficiente de determinação, o teste $\mathrm{F}$ simultâneo para identidade de parâmetros $(a=0$ e $b=1)$ e a raiz do quadrado médio do erro da predição (RQMEP). Calculou-se, ainda, a correlação 
de ranking de Spearman para avaliar se o ranking das produções seria semelhante entre os métodos.

\section{Resultados e discussão}

A análise de variância mostrou que o formato da moldura não afetou $(p>0,05)$ as estimativas de TxAp, TxMort e TxSobr (Tabela 2).

Tabela 2 - Comparação dos dois formatos de moldura metálica para estimar características da dinâmica de perfilhamento do capim-tanzânia

\begin{tabular}{ccccc}
\hline Característica & $\begin{array}{c}\text { Média } \\
\text { Quadrado }\end{array}$ & $\begin{array}{c}\text { Média } \\
\text { Retângulo }\end{array}$ & $\begin{array}{c}\text { Variância } \\
\text { Quadrado }\end{array}$ & $\begin{array}{c}\text { Variância } \\
\text { Retângulo }\end{array}$ \\
\hline TxAp & 4,24 & 4,30 & 0,397 & 1,130 \\
TxMort & 1,78 & 1,19 & 1,470 & 0,172 \\
TxSobr & 3,08 & 3,10 & 0,314 & 0,417 \\
\hline
\end{tabular}

De acordo com análise de variância, as médias preditas não apresentaram diferenças. No entanto, as variâncias foram diferentes entre si no teste, indicando que os dois métodos estão considerando variabilidades diferentes para as características.

Podemos observar que o coeficiente de determinação $\left(R^{2}\right)$ foi baixo. Segundo Triola (2008), o $\mathrm{R}^{2}$ é uma medida de ajustamento de um modelo estatístico linear generalizado. Os valores, de acordo com esse autor, variam de 0 a 1 , indicando, em percentagem, o quanto o modelo consegue explicar os valores observados. Quanto maior o $\mathrm{R}^{2}$, mais explicativo é o modelo e melhor ele se ajusta à amostra, como indica a Tabela 3.

Os coeficientes de determinação das variáveis TxAp, TxSobr e TxMort foram 1,9\%, 7,7\% e 11,5\%, respectivamente (Tabela 3). Isto significa que a variável dependente não consegue ser explicada pelos regressores presente no modelo. Apesar do $\mathrm{R}^{2}$ dos formatos das molduras não ser alto (Chaves Neto e Turim, 2003), os valores preditos por estes modelos ainda puderam ser aceitos como semelhantes, como descrito por Chen e Popovich (2002).

Segundo Meyer et al. (2012), a precisão é uma medida de dispersão entre os valores preditos e observados, ou seja, é a variabilidade média da distância entre o valor predito e o valor observado, podendo ser avaliada pela raiz quadrada média do erro de predição (RQMEP). É uma medida capaz de apontar o quanto as predições se adequam aos dados observados. A Tabela 3 evidencia o baixo RQMEP que, para TxAp, TxMort e TxSobr, foi de 1,12, 1,25 e 0,705 perfilhos, respectivamente, demonstrando a acurácia dos dados encontrados nos dois métodos para a determinação da dinâmica de perfilhamento.

Segundo Siegel (1975), a correlação ranking de Spearman é uma medida que exige que duas variáveis se apresentem em escala de mensuração pelo menos ordinal, de forma que os elementos em estudo formem duas séries ordenadas. Com base nesta informação fica perceptível na Tabela 3 que as amostras não foram ordenadas da mesma forma pelos dois métodos.

Tabela 3 - Regressão dos dados obtidos com a moldura retangular em função dos dados obtidos com o quadrado

\begin{tabular}{ccccc}
\hline Característica & $\mathrm{R}^{2}$ & $\begin{array}{c}\text { Valor-p Identidade } \\
\text { de parâmetros }\end{array}$ & RQMEP & $\begin{array}{c}\text { Corr. Ranking } \\
\text { de Spearman }\end{array}$ \\
\hline TxAp & 0,019 & 0,257 & 1,120 & 0,247 \\
TxMort & 0,115 & $<0,001$ & 1,250 & 0,497 \\
TxSobr & 0,077 & 0,106 & 0,705 & 0,220 \\
\hline
\end{tabular}

A falta de significância entre os métodos pode ser justificada pela geometria, que caracteriza o quadrado como um retângulo cuja base e altura têm medidas iguais. Com base nessa afirmação, podemos inferir que a diferença entre os dois tratamentos é o formato da armação metálica, e não a área. Assim, independente do formato, a quantidade de perfilhos por área será a mesma.

Diferente dos resultados obtidos neste trabalho, Gomez e Gomez (1984), avaliando os procedimentos estatísticos para a pesquisa agrícola, observaram que os resultados coletados nas parcelas retangulares apresentaram variabilidade menor do que em parcelas quadradas. Esta disparidade entre os trabalhos pode ser justificada pelo tamanho das parcelas, visto que Gomez e Gomez (1984) utilizaram áreas medindo mais de $10 \mathrm{~m}^{2}$, demostrando que em áreas maiores pode ocorrer maior variabilidade entre os formatos. 
Outra explicação plausível para a desigualdade entre os trabalhos supracitados pode ser dada por Penati et al. (2005), que ao estudarem o número de amostras e a relação dimensão-formato da moldura de amostragem para determinação da massa de forragem de gramíneas cespitosas, relataram que valores maiores são observados quando utilizamse molduras menores $\left(0,49 \mathrm{~m}^{2}\right)$ para estimar a massa de forragem em pastagem, inferindo que plantas cespitosas como o Panicum maximum cv. Tanzânia necessitam de uma área maior em decorrência do hábito de crescimento.

Com a finalidade de se verificar a viabilidade do uso de microparcelas na avaliação de progênies de milho, para fins de seleção, Chaves (1985) concluiu que parcelas retangulares são indicadas quando a área experimental (ou parcela) é heterogênea, em função de algumas características relacionadas ao solo, como retenção de umidade e fertilidade, tornando as parcelas mais homogêneas entre si, apesar de aumentar a heterogeneidade dentro da parcela.

Com base nessa informação, fica claro que em experimento como este, realizado em canteiros, não há necessidade de utilização de armações retangulares, por existir uma homogeneidade em toda área experimental e um espaço entre linhas. Deduzindo, assim, que para haver uma significância entre as armações (retângulo x quadrado) seria necessário utilizar um retângulo com a base três vezes maior do que a altura, para maior representatividade da linha de coleta.

Outro fator que pode ter causado a falta de diferença neste trabalho foi o estresse causado pelo ambiente, tendo em vista que os dados foram coletados no período de baixa produtividade forrageira. As plantas forrageiras apresentam um período de estacionalidade, onde seu crescimento e, consequentemente, perfilhamento cessam ou diminuem, deixando claro que os fatores climáticos exercem grande impacto sobre as variações no ritmo de crescimento das plantas.

Segundo Canto et al. (2002), as cultivares de Panicum maximum apresentam grande estacionalidade na produção forrageira em relação as Brachiarias. Neste sentido é notório o baixo perfilhamento do presente estudo em razão da taxa de aparecimento de perfilhos, com média de 4,3 perfilhos por dia nos dois tratamentos. Duarte et al. (2014), trabalhando com B. brizantha cv. BRS Piatã no outono/inverno, observaram média de 5,17 perfilhos por dia, ressaltando a superioridade da Brachiaria em relação ao Panicum no período de baixa produção forrageira (inverno/outono).

Resultados semelhantes a este trabalho foram relatados por Santos et al. (1999), que observaram TxAp de 4 perfilhos por dia e TxSobr de 3,34 perfilhos por dia. Como o período de estacionalidade ocorre nos meses onde o fotoperíodo é curto, Lemaire e Chapman (1996) destacaram que o fotoperíodo possui influência sobre a taxa de aparecimento de folhas e, consequentemente, sobre a densidade populacional de perfilhos e sua dinâmica, sendo, portanto, a quantidade de luz incidente no outono e no inverno insuficiente para estimular o perfilhamento.

\section{Conclusão}

0 formato da moldura metálica utilizado na dinâmica de perfilhamento do capim-tanzânia não influenciou os resultados obtidos. Sendo assim, sugere-se a avaliação destas respostas em outras estações do ano, primavera e verão, bem como outros tamanhos de molduras, quantidade ou número de avaliações e outras cultivares com hábito de crescimento diferente ao estudado.

\section{Referências}

Barbosa MAAF, Cecato U, Beraldo JA, Yanaka FY, Onorato WM, Peternelli $M$, et al. Influência da eliminação do meristema apical no aparecimento de perfilhos, em quatro cultivares de Panicum maximum Jacq. Reunião Anual Da Sociedade Brasileira De Zootecnia; jul 1996; Fortaleza, CE. Botucatu: SBZ; 1996.

Canto MW, Jobim CC, Cecato U, Castro CRC, Hoeschl AR, Galbeiro S, et al. Acúmulo de forragem e perfilhamento em capim Tanzânia, Panicum maximum Jacq., diferido após pastejo em diferentes alturas. Acta Scientiarum. 2002;24(4):1087-92.

Chaves JC. Tamanho da parcela para seleção de progênies de milho (Zea mays L.) [tese]. Piracicaba: Escola Superior de Agricultura Luiz de Queiroz; 1985. 
Chaves Neto A, Turim ME. Análise de itens pela teoria clássica da avaliação em dados reais do ensino fundamental. IX Seminário IASI de Estatística Aplicada; 7-10 jul 2003; Rio de Janeiro. Rio de Janeiro: IMPA; 2003.

Chen PY, Popovich PM. Correlation: parametric and nonparametric measures. London: Sage; 2002. 95 p.

Difante GS, Nascimento Jr D, Silva SC, Euclides VPB, Zanine AM, Adese B. Dinâmica do perfilhamento do capimmarandu cultivado em duas alturas e três intervalos de corte. R Bras Zootec. 2008;37(2):189-96.

Duarte CFD, Paiva LM, Fernandes HJ, Biserra TT. Perfilhamento de capim-piatã adubado com fontes de fósforo de diferente solubilidade em água no outono em Aquidauana, MS. IV Encontro Cientifico da Zootecnia; dez 2013 - mai 2014; Aquidauana, MS. Aquidauana: Universidade Estadual de Mato Grosso do Sul; 2014.

Freitas AWP. Dinâmica do perfilhamento em pastagens sob pastejo. Trabalho apresentado como parte das exigências da disciplina ZOO 650 - Forragicultura. Viçosa: Universidade Federal de Viçosa; 2000. [acesso 19 abr 2016]. Disponível em: https://tinyurl.com/y9tmdm6z.

Gomez KA, Gomez AA. Statistical procedures for agricultural research. New York: John Wiley \& Sons; 1984.680 p.

Hay MJM, Jones RM, Orr DM. Plant population dynamics in grasslands. In: 't Mannetje L, Jones RM (EE). Field and laboratory methods for grassland and animal production research. Wallingford, UK: CABI Publishing; 2000. p. 123-49.

Hodgson, J. Grazing management: Science into practice. New York: Longman Scientific and Technical; 1990. 203 p.

Lemaire G, Chapman D. Tissue flows in grazed plant communities. In: Hodgson J, Illius AW (EE). The ecology and management of grazing systems. Wallingford, UK: CAB International;1996. p. 3-36.

Meyer PM, Machado PF, Coldebella A, Cassoli LD, Coelho KO, Rodrigues PHM. Validação de modelos de predição das concentrações de nitrogênio ureico no leite do rebanho de vacas holandesas. Rev Bras Saude Prod Anim. 2012;13(3):.860-71.
Pedreira CGS, Mello ACL, Otani L. O processo de produção de forragem em pastagens. 2006 [acesso]. Disponível em: https://tinyurl.com/ya8bm4vy.

Penati MA, Corsi M, Lima CG, Martha Jr GB, Dias CTS. Número de amostras e relação dimensão formato da moldura de amostragem para determinação da massa de forragem de gramíneas cespitosas. $\mathrm{R}$ Bras Zootec. 2005;34(1):36-43.

Santos PM, Corsi M, Balsalobre MAA. Efeito da frequência de pastejo e da época do ano sobre a produção e a qualidade em Panicum maximum cvs. Tanzânia e Mombaça. R Bras Zootec. 1999;28(2):244-9.

Siegel S. Estatística não-paramétrica para as ciências do comportamento. São Paulo: McGraw-Hill; 1975.

Tedeschi LO. Assessment of the adequacy of mathematical models. Agric Syst. 2006;89(2-3):225-47.

Triola MF. Introdução à estatística. Rio de Janeiro: LTC; 2008. 408 p. 